\title{
SIGNIFICAR O MUNDO: A EDUCAÇÃO HISTÓRICA COMO PERSPECTIVA DE ENFRENTAMENTO AO TRABALHO ESCRAVO.
}

\author{
MEANING THE WORLD: HISTORICAL EDUCATION AS A \\ PERSPECTIVE TO FACE SLAVE WORK.
}

\author{
Moisés Pereira da SiLVA*
}

\section{RESUMO}

O intelectual alemão Jörn Rüsen, partindo da problematização da educação na Alemanha da década de 1970, desenvolveu uma proposta de ressignificação da didática da história que a desvincula da chamada pedagogia da instrução e, aproximando ensino de história e teoria da história, pensa o ensino de história a partir do desenvolvimento da consciência histórica dos sujeitos do processo educativo. $\mathrm{O}$ pensamento pedagógico brasileiro produziu, a partir de Paulo Freire e da sua defesa da educação como processo político de desenvolvimento da consciência crítica, proposta que se aproxima e pode dialogar com a escola Alemã. A perspectiva freireana, somada às contribuições de outros intelectuais engajados com a educação no Brasil, constituiu pressuposto teórico para o desenvolvimento de uma prática docente que, situada no contexto rural do sudeste paraense, procurou aproximar o pensamento de Rüsen e de Paulo Freire num ensaio propositivo de educação preventiva ao trabalho escravo. É dessa experiência pedagógica, e das reflexões teóricas nela imbricadas, que trata esse texto. Destarte, o objetivo dessa comunicação é problematizar experiências docentes em quatro comunidades rurais do Estado do Pará, no âmbito da quarta Unidade Regional de Ensino, Marabá, em que se procurou, na perspectiva teórica de Rüsen e Freire, empreender ações pedagógicas de enfrentamento ao trabalho escravo.

\begin{abstract}
The German intellectual Jörn Rüsen, starting from the problematization of education in Germany in the 1970s, developed a proposal to re-signify the didactics of history that detach it from the so-called pedagogy of instruction and, approaching the teaching of history and the theory of history, thinks the teaching of history from the development of the historical consciousness of the subjects of the educational process. The Brazilian pedagogical thought produced, based on Paulo Freire and his defense of education as a political process for the development of critical awareness, a proposal that is close and can dialogue with the German school. The Freirian perspective, added to the contributions of other intellectuals engaged in education in Brazil, constituted a theoretical assumption for the development of a teaching practice that, located in the rural context of the southeast of Pará, sought to bring together the thinking of Rüsen and Paulo Freire in a propositional essay preventive education to slave labor. It is from this pedagogical experience, and from the theoretical reflections involved in it, that this text deals. Thus, the purpose of this communication is to problematize teachers experiences in four rural communities in the State of Pará, within the scope of the fourth Regional Teaching Unit, Marabá, in which, in the theoretical perspective of Rüsen and Freire, it was sought to undertake pedagogical actions to confront work slave.
\end{abstract}

* Doutor em História Social pela Pontifícia Universidade Católica - São Paulo. Professor Adjunto da Universidade Federal do Tocantins (UFT). Professor Adjunto do CFP/UFCG.

E-mail: mosico100@gmail.com. 
PALAVRAS-CHAVE: Docência. Educação Histórica. Trabalho Escravo Contemporâneo.
KEYWORDS: Teaching. Historical education. Contemporary Slave Work.

\section{RESUMEN}

El intelectual alemán Jörn Rüsen, desde el problematización de la educación en Alemania en la década de 1970, desarrolló una propuesta para volver a significar la didáctica de la historia que la separa de la llamada pedagogía de la instrucción y, al acercarse a la enseñanza de la historia y la teoría de la historia, piensa en la enseñanza de historia desde el desarrollo de la conciencia histórica de los sujetos del proceso educativo. El pensamiento pedagógico brasileño producido, basado en Paulo Freire y su defensa de la educación como proceso político para el desarrollo de la conciencia crítica, es una propuesta cercana y que puede dialogar con la escuela alemana. La perspectiva freireana, sumada a las contribuciones de otros intelectuales dedicados a la educación en Brasil, constituyó una suposición teórica para el desarrollo de una práctica docente que, ubicada en el contexto rural del sureste de Pará, buscaba unir el pensamiento de Rüsen y Paulo Freire en un ensayo proposicional. Educación preventiva al trabajo esclavo. Es de esta experiencia pedagógica, $y$ de las reflexiones teóricas involucradas en ella, que trata este texto. Por lo tanto, el propósito de esta comunicación es problematizar las experiencias de enseñanza en cuatro comunidades rurales en el Estado de Pará, dentro del alcance de la cuarta Unidad Regional de Enseñanza, Marabá, en la cual, en la perspectiva teórica de Rüsen y Freire, se buscó emprender acciones pedagógicas para enfrentar el trabajo. esclavo.

PALABRAS CLAVE: Enseñanza. Educacion historica Trabajo esclavo contemporáneo.

\section{INTRODUÇÃO}

O filosofo marxista Antônio Gramsci ${ }^{1}$ vincula ao papel dos intelectuais uma prática engajada que contribui, no campo da cultura, da história e da política, com a assunção da consciência do povo. O esforço de Gramsci é, sob os auspícios da filosofia da práxis marxista, aprofundar a relação entre intelectuais, política e classe social. O intelectual orgânico é, antes de tudo, alguém que toma parte na dinâmica do mundo. Essa práxis, Adolfo Sánches Vázquez ${ }^{2}$ a define como ação humana consciente sobre o mundo e Paulo Freire ${ }^{3}$ a situa como fenômeno de ascensão da consciência sobre o mundo imediato, ou a passagem da consciência ingênua à consciência crítica ou transcendente sobre o mundo. Nessa perspectiva, o papel do intelectual, e em consequência da educação, não é a erudição em si, mas a reflexão propositiva ancorada na realidade. É nesta perspectiva que a nossa discussão parte do contexto da prática. E foi nesse contexto da atuação docente, de trabalho no Sistema de Organização Modular de Ensino, SOME, que se pensou, como demanda dos sujeitos do processo educativo, uma proposta de educação que significasse alguma minoração aos dramas dos povos do campo, cujas problemáticas, além da violência agrária, inclui o trabalho escravo.

$\begin{array}{ll}1 & 2001 . \\ 2 & 1977 . \\ 3 & 1987 .\end{array}$


Situando o contexto, nos referimos a quatro escolas de assentamentos rurais localizados no sudeste paraense, mais especificamente em duas comunidades do município de Piçarra-PA e outras duas escolas do município de São João do Araguaia-PA. As duas escolas do município de Piçarra nasceram de dois assentamentos, o Oziel Pereira e Anajás, ambos marcados pela ocupação e da luta sangrenta pela terra na antiga Fazenda Bamerindus, que entre outras formas de violência, submeteu trabalhadores à escravidão. $\mathrm{O}$ mesmo se deu no contexto de formação do assentamento Primeiro de Março e Ponta de Pedras, também comunidades nascidas de vitórias na luta pela terra, terra na qual também se empregava mão de obra escrava. Essa luta pela terra, que não termina, como a luta contra o trabalho escravo, constituem os primeiros capítulos das histórias destas comunidades. Considerou-se, nesse cenário, o desenvolvimento de atividades pedagógicas que, ao mesmo tempo em que colaborassem para o desenvolvimento da consciência histórica ${ }^{4}$ sobre o passado, contribuísse também na prevenção de novos enredamentos em práticas escravistas, ameaça contínua.

Nos primeiros contatos com as comunidades, ainda em 2016, desenvolveu-se uma série de atividades didáticas que envolviam pesquisa quantitativa, com vistas à construção de um inventário da situação socioeconômica dos alunos e pesquisa qualitativa em que foram motivados a escreverem sobre suas trajetórias de vida. Desde esse primeiro momento percebeu-se que a identidade constituía um problema para muitos sujeitos da comunidade que, embora reconhecessem desafios como o trabalho escravo e a violência da luta pela terra, procuravam identificar as suas próprias situações como de fazendeiros e as histórias das famílias desvinculadas das histórias daqueles outros que eram mais pobres, e por isso se tornavam escravos.

No esforço de estimular a identificação dos alunos com a história coletiva, passou-se a tematizar os problemas da comunidade, sempre procurando acentuar o lugar de cada um no tecido social de forma a reforçar o sentido plural dos dramas comunitários. Assim, depois da constituição de uma compreensão sobre esse aspecto do imaginário dos alunos, propôs-se, a partir da metodologia da pesquisa oral ${ }^{5}$, que realizassem perquirição sobre a história da comunidade procurando identificar como suas próprias histórias se cruzavam na reconstituição da história coletiva. Isso significou que, diferente da narrativa comum sobre o processo migratório, precisaram, mais que isso, dizer como surgiu a comunidade e que posição ocupavam nesse processo de constituição da história local. O esforço pedagógico foi da promoção de uma leitura de mundo

4 Consciência histórica pensada na perspectiva de Jörn Rüsen conforme seus estudos publicados no Brasil $(2006 ; 2001)$ e as contribuições interpretativas de Schmidt e Martins (2011) e Schmidt e Urban (2016).

5 Considerando a menoridade de alguns alunos, ficou combinado, com todos, que os usos acadêmicos que viessem ocorrer posteriormente seriam feitos com a substituição dos nomes por outras formas de identificação. 
subsidiada por uma compreensão freireana do processo educativo ${ }^{6}$; de sujeitos que se reconhecem na história e que, ao mesmo tempo, reconhecem nessa história a chave de leitura do presente e a possibilidade de constituição de um futuro melhor.

\section{O CAMPO DE ATUAÇÃO: A PERSPECTIVA DOCENTE}

O Sistema Modular, ou simplesmente SOME, como é conhecido, é um programa que, na perspectiva da educação do campo, pretende ser alternativa à histórica incapacidade do poder público do Pará em oferecer educação regular às comunidades rurais, isoladas pela distância, pelas dificuldades de acesso e marcadas pelo abandono. Trata-se, portanto, de um programa que nasceu para ser provisório. Mas o transitivo foi ficando até ficar definitivo. Foi ficando não porque a precariedade tenha sido superada, mas porque é conveniente, do ponto de vista econômico, fazer funcionar um modelo educacional cujo custo se limita quase exclusivamente ao salário dos professores, em número sempre reduzido. As aulas, quando os professores não podem dispor de escolas municipais cedidas para uso em determinados turnos, funcionam improvisadas em espaços que vão desde igrejas a prédios de associações. E mesmo havendo um consenso de que esse não é o ideal de atendimento educacional, o SOME nasceu no Estado do Pará em 1982 e continua sendo, para muitos jovens e adolescentes a única possibilidade de acesso à educação em nível médio.

Embora produto das contingências, e em que pesem os problemas já indicados, alguns pesquisadores ${ }^{7}$ dedicados ao estudo da educação modular no Pará avaliam positiva a iniciativa por oportunizar a milhares de jovens e adolescentes o acesso à educação. Além da garantia da educação, é consenso o entendimento do Sistema Modular como estratégia de permanência dos jovens e adolescentes no campo. O mundo urbano representa, nestes estudos, uma ameaça permanente de ruptura com o mundo rural ao qual os adolescentes e jovens estão ligados. Brayner $^{8}$ entende o SOME como uma proposta de educação do campo cujas diretrizes, além de reconhecer os desafios de homens e mulheres na luta pela permanência na terra, devem também fazer frente a propostas que possam submeter o mundo rural ao mundo urbano, ou que contribuam para a submissão do "trabalhador do campo a processos de dominação e de exploração e impõem

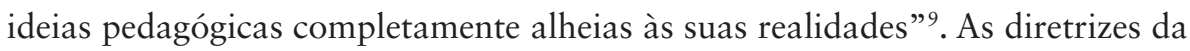
educação básica do campo indicam um trabalho substanciado pelas peculiaridades da vida camponesa. E, na teoria, não tratar-se-ia apenas de adequação ao

6 Especialmente as produções de Paulo Freire $(1987 ; 1989 ; 1996 ; 1997 ; 2000)$ que tematizam a educação como processo de autonomia.

7 QUEIROZ, 2010; BRAYNER, 2013; PEREIRA, 2016.

82013.

9 Op. Cit., p. 66. 
calendário das atividades agrícolas, mas sobretudo, de uma proposta pedagógica ancorada em conteúdos curriculares e valores do contexto em que se dá essa modalidade de educação.

Mas se o Estado não oferece infraestrutura para o funcionamento da educação nessas comunidades é de se supor, por consequência, que a estrutura pedagógica também esteja comprometida. De fato, o processo de ensino circunscreve-se ao professor, suas possibilidades e seus limites. O livro didático, que só chega à escola se o professor encontrar meios de fazê-lo chegar, é quase exclusivamente o único recurso possível sem algum investimento financeiro particular. O currículo de ensino, definido a partir das escolas regulares, na prática diz respeito a conteúdos que nada ou quase nada têm de relação com o contexto daquelas comunidades. Esse é o caráter mais problemático do Sistema Modular e, supõe-se aqui, esse caráter explica o estranhamento dos alunos em relação a temas tão intrínsecos à sua história e ao seu dia-a-dia, como tópicos da história agrária e trabalho escravo contemporâneo.

Procurou-se, nestas comunidades, em face da conjuntura percebida, tematizar o trabalho escravo e a questão agrária empreendendo dinâmicas pedagógicas que possibilitassem aos alunos a ampliação da compreensão de si na leitura da palavra. $\mathrm{O}$ recurso à metodologia da pesquisa oral pretendeu que os alunos percebessem, na imbricação de suas próprias histórias com a história mais geral, da comunidade, que os problemas coletivos lhes dizem respeito. O exercício de instar os alunos a relerem suas histórias nas lembranças dos velhos $^{10}$ da comunidade fez emergir o tema do trabalho escravo no jogo das narrativas; ora como elemento do passado; ora, no presente, como problema de quem precisava trabalhar e só encontrava escravidão. Ao mesmo tempo em que o contexto de trabalho docente é problematizado, se discute as possibilidades de inovação pedagógica à luz do pensamento rüseniano aproximado ao de Freire no enfrentamento ao trabalho escravo em comunidades rurais do sudeste paraense.

\section{O CAMPO DE ATUAÇÃO: A PERSPECTIVA DISCENTE}

Para Freire a práxis docente "que não sendo 'blábláblá', nem ativismo, é ação e reflexão" 11 é substanciada por competências científica e política ${ }^{12}$. Esses pressupostos fundamentam a problematização do campo de atuação docente, problematização que, no âmbito da competência científica, requer conhecimento da realidade. Nessa perspectiva, foram desenvolvidas pesquisas, de caráter

10 O termo "velhos" é aqui utilizado muito mais num sentido de aproximação efetiva e afetiva do passado do que de indiferença à uma fase da vida. É também esse o sentido empregado por Barreto (1992), Rubem Alves (2005), Simone de Beauvoir (1970) e Ecléa Bosi (1994).

11 FREIRE, 1987, p. 21.

12 FREIRE, 1997. 
quantitativo, através de questionários estruturados com quatorze perguntas. As perguntas versavam sobre a faixa etária dos respondentes, o tipo de lugar que viviam e a condição da moradia - nesse caso, se na vila ou na área rural e se como dono, posseiro, agregado ou de aluguel - para os que possuíam terra, a medida e os usos da terra. Por fim, nesse momento inicial, três perguntas sobre trabalho escravo contemporâneo, se ainda havia trabalho escravo, se sabiam o que é e se conheciam alguém que já tinha sido escravo. Seguiu-se a esse momento, a pesquisa qualitativa, que pretendeu reconstituir a história da comunidade a partir da metodologia da história oral.

Os dois momentos da pesquisa tiveram como resultados distinções muito claras entre a compreensão do trabalho escravo, como também da questão agrária, reveladas na pesquisa quantitativa, realizada a partir dos formulários estruturados, e a reformulação desses mesmos conceitos no processo de pesquisa qualitativa, ou seja, de reconstituição da história da comunidade a partir da memória e da metodologia da pesquisa oral.

Por opção metodológica optou-se pela análise dos dados coletados na comunidade Oziel Pereira, no município de Piçarra-PA. Nessa comunidade, trabalhando com três turmas de ensino médio, 58 alunos responderam ao questionário. O perfil autodeclarado apontou que $84 \%$ dos alunos viviam em lotes rurais e deste número, $10,34 \%$ se declararam fazendeiros, o que, na análise dos dados indicou que aqueles alunos cujas famílias tinham lotes superiores a 5 alqueires ${ }^{13}$, medida dos lotes demarcados pelo Instituto Nacional de Colonização e Reforma Agrária, INCRA, procuravam demarcar uma distinção em relação aos assentados definindo o imóvel familiar como sítio ou fazenda. Sobre a luta pela terra, $62 \%$ disseram ser errado invadir terras ${ }^{14} \mathrm{e}$, na discussão, houve quem defendesse que invasor de terra deveria morrer. Sobre o trabalho escravo, 56 alunos, ou $96,5 \%$, declaram ter ouvido falar e saber o que é o trabalho escravo contemporâneo. Mas, na fase de discussão sobre os dados, o conhecimento sobre trabalho escravo contemporâneo apareceu confundido com a escravidão colonial. Apenas 1 aluno conhecia alguém que tinha sido escravo e demonstrou conhecer o conceito.

Nos diálogos sobre o questionário, momento em que os dados quantitativos possibilitaram uma problematização qualificada, ficou claro que muitos dos alunos que diziam morar em sítio queriam, assim, distinguir lote ganho do INCRA de lote comprado. Ter um sítio significava não ter lote, não ser assentado. Estes não eram fazendeiros apenas porque o lote lhes parecia insuficiente para essa condição, embora bastasse para a distinção em relação aos assentados. Os

13 Nas unidades de medidas agrárias um hectare corresponde a $10.000 \mathrm{~m}^{2}$. No sul do Pará um alqueire de terra é igual a 2,72 hectares, ou $27.200 \mathrm{~m}^{2}$ de terra.

14 Algumas famílias, tendo chegado à região depois da fase luta pela terra, adquiriram seus lotes comprando lotes junto aos assentados. 
valores representados no debate pelos alunos, inclusive a posição sobre a luta por terra, constituíam parte do imaginário e dos valores substanciais nos discursos das elites agrárias da região. Ficou muito claro que, em relação ao trabalho escarvo, os alunos o relacionavam com a escravidão colonial, vez que, embora declarassem ter aprendido sobre o tema na escola, não o reconheciam como fenômeno do presente. Negro, senzala, correntes e tortura foram as palavraschave no entendimento que tinham sobre escravidão contemporânea. $\mathrm{O}$ aluno que conhecia um caso de trabalho escravo se referia ao passado da Fazenda Bamerindus e conseguiu, inclusive, relacionar a existência de trabalho escravo às pressões pelo assentamento das famílias na fazenda, ou seja, que naquela fazenda cometiam crimes e que isso justificava a ocupação. Quanto à definição de trabalho escravo consagrada na Lei 10.803/2003, que alterou o Artigo 149 do Código Penal Brasileiro, fragmentos do discurso discente vislumbravam o fenômeno, mas apenas como realidade que lhe era estranha.

É relevante que essa pesquisa evidencie sérios problemas de identidade. E isso não é especificidade dos alunos da Escola Estadual Maria Alice Silveira Lima, situada na Vila Oziel Pereira ${ }^{15}$. O mesmo drama, da identidade opressora hospedeira ${ }^{16}$ da consciência do oprimido, aparece nas escolas da Vila Anajás, Ponta de Pedras e Primeiro de Março. Não é possível, porém, enfrentar o trabalho escravo entre pessoas que se identificam com o opressor e desde Casaldáliga ${ }^{17}$ que o trabalho escarvo no campo aparece relacionado ao latifúndio. Estudos $^{18}$ vêm demonstrando que embora o trabalho escravo no campo não esteja circunscrito à exploração dos trabalhadores por fazendeiros, inclusive pelo agronegócio, é na superexploração do trabalhador que se dá esse fenômeno, mesmo quando o explorador é um pequeno proprietário.

Então o trabalho que pareceu mais urgente era de, no contexto das discussões curriculares, facilitar o desenvolvimento da consciência histórica, ou na acepção freireana, a passagem da consciência ingênua à consciência crítica. Foi para esse caso que entendeu-se oportuno o desenvolvimento de um projeto de educação que repusesse, sob a forma de memória, a história da comunidade como objeto de estudo. A proposta foi, a exemplo da Escola da Vila Primeiro de Março, que o aluno contasse a história da comunidade desde a ocupação e que, ao mesmo tempo, resgatasse a memória familiar nesse processo. Mas havia

15 A educação nas vilas se liga a uma escola sede, quase sempre muito distante de onde ocorrem as aulas. As aulas na Vila Oziel Pereira e na Vila Anajás estavam ligadas à Escola Estadual Maria Alice Silveira Lima e as aulas nas vilas Primeiro de Março e Ponta de Pedras tinham como sede a Escola Estadual de Ensino Médio Dr. Abel Figueiredo.

16 Para Paulo Freire, o estado de opressão pressupõe a dualidade como condição existencial do oprimido. Assim, "hospedando" o opressor cuja "sombra" eles "introjetam", são eles e ao mesmo tempo são o outro (1983, p. 52). O êxito na manutenção da condição de opressão está na força da verdade do opressor na consciência ingênua do oprimido.

171971.

18 ESTERCI, 1987; BRETON, 2002; FIGUEIRA, 2004; SILVA, 2016; 2019. 
aqueles que chegaram depois. Havia, inclusive, os que moravam apenas na Vila porque estavam ali na condição de peões de fazendeiros que tinham terras nos arredores. Também esses tinham o que falar. Todos precisavam falar de como chegaram até ali, chegar que não se limitava à migração, mas também da trajetória de vida, de como era a sua história com a comunidade. Houve grupo que reconstituiu essas histórias com fotos; houve quem falasse sobre a memória de uma castanheira que caiu no meio do assentamento e que depois do susto, quem precisasse falar para todos -fazer um discurso - subia no seu tronco. E, incrivelmente, houve a história da própria escola do município em que ocorriam as aulas do ensino médio, uma escola construída no embate entre o prefeito e as lideranças do movimento sem-terra.

É importante dizer que esse momento foi atravessado por uma série de atividades pedagógicas sobre o trabalho escravo. Além de textos, como a cartilha Escravo, nem pensar! ${ }^{19}$ e material de apoio ${ }^{20}$ da Comissão Pastoral da Terra, CPT, houve a exibição do documentário Nas terras do bem viráa ${ }^{21}$, debates e outras atividades formalizadas na estrutura curricular a partir do projeto Educar para a liberdade ${ }^{22}$, apresentado à Secretaria de Educação para fins de complementação de carga horária. Os alunos, ao mesmo tempo em que pesquisavam sobre a história da comunidade, tinham subsídios para desenvolverem a crítica dos dados que lhes eram apresentados a partir da memória dos velhos.

As construções narrativas, a partir desse processo formativo apresentaram elementos constituidores de "novas" histórias coletivas, uma nova estética discursiva. A beleza, ao mesmo tempo em que se deixava ver na simplicidade da vida reconhecida nua e crua, estava também na dureza da luta que inspirava não só a firmeza da cidadania frente a outros desafios, mas, especialmente, em relação à importância da reprodução da vida com liberdade e não nas tramas da escravidão.

\section{A COMUNIDADE, A TERRA, O TRABALHO E A EDUCAÇÃO HIS- TÓRICA}

A Vila Oziel Pereira nasceu no contexto de luta pela terra na segunda metade da década de 1990. A repercussão midiática do Massacre de Eldorado dos Carajás ocorrido em abril de 1996 terminou forçando o governo à atenção sobre as reivindicações dos assentados da Fazenda Bamerindus cuja liderança, Oziel Pereira, tinha sido um dos assassinados pela polícia na chamada curva do $\mathrm{S}$, no município de Eldorado dos Carajás. Alguns alunos lembraram que

\footnotetext{
19 REPÓRTER BRASIL, 2012.

20 COMISSÃO PASTORAL DA TERRA, 2013.

21 RAMPAZZO, 2007.

22 SILVA, 2016.
} 
as lideranças do Movimento faziam reuniões com "as pessoas sem nada" 23 de Eldorado, Parauapebas e até de Marabá explicando que "a Fazenda era ilegal e que tinha muita terra para quem não tinha nada" ${ }^{24}$. Dívidas com o Estado e a existência de trabalho escravo eram as ilegalidades identificadas pelos narradores. A pressão sobre o Estado agilizou o processo de assentamento das mais de 1.200 famílias que esperavam por um lote de terra na Bamerindus. A história da comunidade, estruturada a partir das narrativas dos alunos, é longa, triste e, ao mesmo tempo, linda.

De uma outra comunidade, a Primeiro de Março, distante 20 quilômetros de Marabá, embora pertença administrativamente ao Município de São João do Araguaia, soube que nos meses que se seguiram ao Massacre de Eldorado dos Carajás o Movimento dos Sem Terra, MST, apoiado pela Comissão Pastoral da Terra, CPT, especialmente a partir do apoio pastoral do padre Luis Muraro, iniciou um trabalho de base com as lideranças comunitárias dos bairros pobres de Marabá. As reuniões com as lideranças ocorriam em igrejas, escolas e associações. Nestas ocasiões, além de discutir os problemas sociais da comunidade, as lideranças do MST orientavam o povo sobre terras griladas por fazendeiros e que poderiam ser ocupadas por famílias que, embora vivessem na cidade, não tinham emprego, moradia, ou terra para trabalhar no campo. O Movimento fez um levantamento das famílias e, em dezembro de 1997 iniciou-se a ocupação da Fazenda Pastoriza, no Município de São João do Araguaia. Nas reuniões, segundo as narrativas de alguns alunos ${ }^{25}$, o MST apresentou vários motivos para a invasão da fazenda, dentre eles, exploração ilegal de madeira, trabalho escravo e sonegação de impostos. O povo saiu em romaria. Primeiro acampou perto da fazenda, onde foi celebrada uma missa. Ali as mais de 1.500 famílias foram organizadas em grupos e foram formados também as equipes de trabalho entre as quais foram distribuídas atividades como lazer, segurança, educação e saúde escolhendo entre os membros das famílias as pessoas para estas funções. Finalmente, decorrido alguns dias, realizou-se a grande assembleia para decidir sobre a entrada na fazenda. Foi uma grande expectativa. Muita gente teve medo e voltou para os barracões na periferia de Marabá. Mas muita gente decidiu enfrentar. Em primeiro de Março de 1997 à noite, mulheres, homens e crianças, andando e cantando, entraram na Fazenda Pastoriza. Mais um passo da luta. De acampado em 1997 o povo passou à condição de assentado em 1998 e em 2002, ocupando seus lotes, puderam também ganhar a casa na Vila Primeiro de março.

Essas narrativas foram colhidas dos textos, e dos diálogos provocados pelos textos, produzidos pelos alunos a partir da pesquisa qualitativa em que

23 DISCENTE A, 2018.

24 DISCENTE E, 2018.

25 DISCENTE A; DISCENTE C; DISCENTE E, 2018 
lhes foi solicitado contarem a história do lugar em que viviam. A partir dessa atividade, os alunos foram provocados a explicarem o que era o trabalho escravo, que em algumas narrativas aparecia como motivo da ocupação das fazendas. Diferente da Vila Oziel Pereira, onde apenas um aluno ${ }^{26}$ identificou o que entendia por trabalho escravo com as características tipificadas no artigo 149 do Código Penal, na Vila Primeiro de Março essa relação apareceu com mais frequência não só à luz do Código Penal, mas também dos estudos sobre o tema. Para estes alunos, o trabalho escravo estava relacionado com os assassinatos de trabalhadores que aconteceram no interior da fazenda, cuja motivação seria de não lhes pagar pelos trabalhos realizados.

O projeto educação histórica e prevenção ao trabalho escravo proposto aos alunos das escolas que compõem o circuito no qual, à época, estava lotado um dos autores teve como metodologia a fomentação do diálogo e a troca de saberes sobre o trabalho escravo contemporâneo. O papel do professor nesse processo foi de mobilizar os alunos problematizando suas próprias falas nos textos escritos e, assim, contribuir para que pudessem construir conceitos sobre o trabalho escravo e propusessem estratégias de superação e prevenção. $\mathrm{O}$ material de apoio, impresso e em vídeo, foi muito importante para a reformulação do conceito de trabalho escravo.

Do ponto de vista docente tem sido uma experiência muito rica, especialmente pelo fato de desenvolver esse trabalho no campo, na modalidade educação do campo. Entende-se aqui que a educação do campo é a perspectiva de garantia do direito do povo do campo a "uma educação pensada desde o seu lugar e com a sua participação, vinculada à sua cultura e às suas necessidades humanas e sociais" ${ }^{27}$. Ao mesmo tempo em que é esforço de criação de possibilidades de permanência no campo para homens e mulheres, que de outra forma migrariam em busca de estudos para si ou para os filhos. A educação do campo é também estratégia de empoderamento dos sujeitos que sabendo de si e do mundo nele atuam de modo a transformá-lo tendo suas necessidades pessoais e coletivas como o sentido dessa ação. É a própria Lei de Diretrizes e Bases da Educação Nacional, Lei 9.394/96, popularizada como LDB, que determina sejam feitas adaptações na oferta da educação básica no meio rural. Essas adaptações, dentre outras recomendações, devem consistir em "conteúdos curriculares e metodologias apropriadas às reais necessidades e interesses dos alunos da Zona Rural”. (Art. 28, I). No caso do Pará, especialmente a partir da criação das Diretrizes Operacionais para a Educação Básica nas Escolas do Campo em 2002 houve um grande esforço discursivo que pretendia, tendo a LDB como orientação, aproximar a proposta educacional do campo com as

26 DISCENTE B, 2018. Segundo essa narrativa havia à época, na Fazenda Bamerindus, guardas armados que impediam a saída de quem estivesse devendo para a fazenda.

27 CALDART, 2002, p. 26. 
reinvindicações dos movimentos sociais rurais, o que se explica, sobretudo, a partir das iniciativas pedagógicas do Movimento dos Sem Terra. O que implica dizer que houve uma reação do Estado que pretendeu tornar política pública o que as escolas do MST faziam na prática. A letra da Lei, no entanto, não foi suficiente nem para criar a estrutura, que requeria disposição financeira do Estado, nem para mudar a concepção de educação e sociedade com que operam os representantes do Estado responsáveis pelo Sistema Modular.

Nesse sentido, é idílica a avaliação de Nazaré de Moraes Brayner ${ }^{28}$ sobre a política educacional que criou as Diretrizes Operacionais da Educação do Campo no Pará. Segundo ela, essa política valorizou a identidade cultural dos sujeitos do campo e estabeleceu um marco na formulação de uma educação condizente com as suas necessidades, o que representou "um salto de qualidade na forma de pensar a escola, relacionando-a a construção de sociedade e de desenvolvimento que se deseja concretizar para cidadãos e cidadãs, que vivem no campo e ou do campo" ${ }^{29}$. O problema é que essa política não teve repercussão prática e, do currículo à estrutura de ensino, o que se tem é a desconstrução desse discurso. É necessário problematizar também a avaliação de Adeíse Gomes Queiroz $^{30}$, para quem o SOME foi, num período de grande déficit na oferta de ensino público, a experiência mais significativa de educação do campo no Estado do Pará. O problema -e essa é a crítica mais contundente - é saber se apenas aulas no meio rural são suficientes para a caracterização da educação do campo. Considerando a LDB e as Diretrizes Curriculares para a Educação do Campo, a resposta é não. A exemplo do que se vem discutindo, a partir dos assentamentos de São João do Araguaia-PA e Piçarra-PA, nem currículo nem material didático são pensados na perspectiva do campo e para o campo. Na prática, o Sistema de Ensino Modular se distingue da educação regular apenas pela localização geográfica da escola, que é no campo.

Foi nesse quadro desafiador que se procurou, inclusive com apoio de outros professores, incluir a temática do trabalho escravo no currículo de História. Nesse ponto, a primeira questão posta a esta pretensão foi da razoabilidade de se falar da disciplina de história a partir da temática do trabalho escravo. É difícil falar de sujeitos e contextos específicos quando os fins impostos à educação, substanciados em material didático, métodos de ensino e formas de avaliação massivos, não deixam dúvidas de que a história que se pensa na escola, salvo poucas exceções, é uma ficção com pouca margem para que se possa vislumbrar as pessoas e suas realidades concretas. Num sistema premido pelas demandas do Exame Nacional do Ensino Médio (Enem), não há espaço para as singulari-

282013.

292013, p. 64.

$30 \quad 2010$, p. 53. 
dades, muito embora o discurso, nos parâmetros curriculares nacionais, girem em torno do respeito à diversidade, inclusive às diversidades regionais. Não há espaço para a existência dos sujeitos, mesmo quando todo o discurso seja o da cidadania sob o lema da formação para a autonomia. Não há espaço para existências concretas mesmo se tratando de educação do campo.

A educação pública paraense, salvo poucas exceções, ao mesmo tempo em que não consegue atender as exigências da educação técnica, para o mercado de trabalho, também não consegue significar o processo educativo, o que a torna desinteressante do ponto de vista do aluno, que em muitos casos, termina por abandonar a escola ou, em outros tantos casos, sequer chega a ela. Um estudo do Instituto Nacional de Estudos e Pesquisas Educacionais, INEP, publicado em 201731, analisando dados do senso escolar do Estado do Pará entre os anos de 2014 e 2015, verificou que a evasão escolar, considerando todas as etapas do ensino médio, é de 16,3\%. Ainda em 2017, segundo o jornal Diário do Pará32 , relatório publicado pelo Fundo das Nações Unidas para a Infância, UNICEF, apontava que 175 mil pessoas, com idade entre 4 e 17 anos estavam fora da escola no Pará, chegava-se ao percentual de $25 \%$ quando consideradas as crianças com idade entre 4 e 5 . Chama a atenção, na literatura ${ }^{33}$ que discute a evasão escolar, o paradoxo da crescente oferta de ensino em descompasso com o significativo número daqueles que se mantêm fora da escola, ou porque não ingressaram no sistema de ensino ou porque dele evadiram. Os dados possibilitam uma diversidade de interpretações sobre o fenômeno da evasão. Mas certo é que existe uma anomalia entre a representação que a escola faz do mundo e o que o mundo é na experiência dos alunos. Essa incongruência é que torna a escola desinteressante no horizonte de expectativa discente. As demandas sociais são concretas e urgentes, e na incapacidade da escola em atendê-las, falta sentido manter-se na escola.

O desencontro entre o mundo da escola e o mundo dos alunos é uma das chaves de leitura para o fenômeno da evasão escolar. Se esse desacordo não explica toda a sua complexidade, certamente aponta indícios fundamentais para o seu entendimento. O estudo de Carraher e Schliemann ${ }^{34}$ demonstra com muita propriedade que a instituição escolar, ao se afastar do mundo dos vivos, especialmente daqueles que precisam lutar todos os dias por sua sobrevivência, torna a vida um fardo para aqueles que estão obrigados a frequentá-la. Esse caráter da escola não explica apenas a evasão, explica também o choque das narrativas. Quando os alunos tiveram que responder ao questionário sobre como

31 LIMA e MAGNO, 2017, p. 1.

32 MAGNO, 2017.

33 CARRAHER, CARRAHER e SCHLIEMANN, 1989; NERI, 2009; WILLINGHAM, 2011; MARCHESI, 2005.

34 Op. Cit.. 
compreendiam o seu mundo, sem grandes reflexões, apresentaram esse mundo a partir de uma narrativa em que eles próprios não se reconheciam afetados pela violência, como a do trabalho escravo. Foi preciso retomar a história, com toda a sua reposição dramática, para que a consciência de pertencimento possibilitasse uma nova narrativa.

\section{A EDUCAÇÃO HISTÓRICA: APROXIMAÇÕES ENTRE JÖRN RÜSEN E PAULO FREIRE}

Jörn Rüsen elaborou o seu conceito de educação histórica a partir da crítica ao modelo alemão de formação docente que concebia a didática da história "como uma ferramenta que transporta conhecimento histórico dos recipientes cheios de pesquisa acadêmica para as cabeças vazias dos alunos" ${ }^{35}$. A função da história naquele contexto era ser mestra da vida, tarefa amparada pelo monumento de narrativas e crônicas sobre homens e fatos exemplares. Rompendo com os limites dessa compreensão, a educação histórica é, na proposta de Rüsen, a busca de sentido de orientação temporal a partir da articulação entre as demandas do presente, a experiência do passado e a expectativa de futuro. Não se trata apenas da centralidade do sujeito do processo educativo, mas também da constituição de sentido a partir desse sujeito que articula as diferentes temporalidades de acordo com suas contingências. $\mathrm{O}$ aprendizado histórico, nesse sentido, é uma forma de inteligibilidade do passado à luz do presente, ao mesmo tempo em que é perspectiva de ação dos sujeitos históricos no sentido de construção do seu futuro. A autonomia é, em última análise, o objetivo dessa proposta de educação.

A autonomia é, nesse sentido, o poder de autodeterminação e a educação é a possibilidade de existência de liberdade e da autonomia. A educação de que fala Freire é a ponte entre a consciência ingênua e a crítica, assim como para Rüsen a educação histórica serve ao desenvolvimento da consciência histórica, sentido prático da experiência do tempo. É, pois, na aproximação teórica entre Freire e Rüsen que se tem empreendido práticas, na perspectiva da educação histórica, que contribuem com o enfrentamento ao trabalho escravo a partir de um lugar e de sujeitos determinados, a educação pública estadual no Pará e jovens e adolescentes de áreas de assentamentos rurais no sudeste paraense. Há que se dizer, nessa acepção, que a crítica desenvolvida por Paulo Freire ao modelo educacional, que entre outros adjetivos foi qualificado como educação bancária, tendo como pressuposto de superação a práxis docente que "é ação e reflexão" ${ }^{36}$ substanciados por competência científica e política ${ }^{37}$, cabe ao mo-

35 2016, p. 8.

36 FREIRE, 1987, p. 21.

37 FREIRE, 1997. 
delo de educação estadual paraense que sob a estética discursiva da educação do campo relega milhares de jovens e adolescentes ao abandono. Foi, portanto, a partir dessa problemática do contexto de atuação docente que, como forma de enfrentamento daquilo que atravanca a educação, entendida como processo humanizador e libertador, especialmente enfrentamento ao trabalho escravo, se desenvolveu uma proposta de ensino-aprendizagem que, reconhecendo o protagonismo dos alunos e valorizando-os como sujeitos que são, referendado nos pressupostos da educação histórica e da teoria freireana, foi desenvolvido o projeto que procura, pedagogicamente, prevenir os alunos em relação ao trabalho escravo contemporâneo.

As pesquisas e a força da realidade têm reforçado a conviç̧ão, teoricamente inspirada em Gramscii ${ }^{38}$ e Sartre ${ }^{39}$, sobre a relevância social dos intelectuais e, por extensão, dos espaços de produção de saberes. Intelectual aqui não é apenas o homem da academia, mas todos os sujeitos envolvidos no processo de produção do saber, admitindo-se a escola como um desses espaços. O professor, portanto, é um intelectual. E se cabe ao intelectual o engajamento social, muito maior deverá ser o papel do professor e da escola no esforço de transformação do mundo dos homens num mundo mais humano. Paulo Freire, à medida que entende a educação como um ato político, propõe ao professor também o protagonismo militante sob a forma do que chama de competência política. Em Gramsci e em Sartre os intelectuais são atores das mudanças sociais. Aliás, foi privado da sua própria dignidade que o italiano Antônio Gramsci, à época prisioneiro político do fascismo italiano, postulou a produção intelectual como uma forma de intervenção prático-política. Por que reconhecia que os intelectuais estão ligados a determinadas classes e, por isso, suas ações tendem a favorecer essas classes, Gramsci considerou orgânica a forma de intervenção desses sujeitos. O intelectual orgânico é aquele que se desloca da torre de marfim para situar-se na concretude da vida, e por isso dos conflitos e da luta do povo em relação ao qual, na sua função específica procura significar.

A crise que a sociedade brasileira atravessa, que não é apenas político -econômica, requer dos professores, e das escolas em que atuam, uma posição frente à diversidade de desafios que se interpõem à dignidade humana, dignidade sob riscos nas suas mais variadas dimensões. Em tempos da defesa, sob o argumento da escola sem partido, de um espaço escolar que não sirva ao desenvolvimento do pensamento crítico, é preciso dizer que a educação histórica pressupõe o reconhecimento, nas experiências pretéritas, dos fundamentos daquilo que atravanca o presente e que pode comprometer a perspectiva de um futuro melhor, mais digno e humano. A escola é o lugar da esperança. E espe-

382001.

$391970 ; 1989$. 
rança, como preconizava Paulo Freire, é a possibilidade de sonhar, de amar e de viver reconhecendo a vida com seus desafios e os meios e possibilidades de superação destes desafios. Reconhecer o que atravanca a vida é o primeiro passo da necessária passagem da consciência ingênua à consciência crítica, passagem que requer uma educação que, não sendo ingênua, é problematizadora.

A educação ingênua, conforme Freire, é aquela que, sobretudo fundada na memorização de fatos, datas e regras confunde instrução com educação. A questão central, portanto, é de promoção de uma educação que, atenta ao mundo dos viventes, possa constituir-se num meio de transformação qualitativa do mundo. Nesse processo, como se procurou demonstrar, a experiência histórica desvelada pela memória dos alunos subsidiou tanto reflexões acerca de conteúdos específicos da proposta curricular, quanto o debate sobre o trabalho escravo contemporâneo.

Considerando os pressupostos de uma educação significativa e libertadora, de desenvolvimento da consciência histórica, por isso, de passagem da consciência ingênua à consciência crítica, não se poderia, no desenvolvimento da prática docente numa das regiões que, historicamente, tem maior incidência de casos de trabalho escravo, ignorar a necessidade de uma educação que contribua com o seu enfrentamento. O esforço, enfim, é de emersão da mesmice implícita no cotidiano para, olhando sobre esse cotidiano, criar alternativas de intervenção e mudança no curso dessa vida cotidiana. É o impulso de negação do que se tem gestado enquanto política educacional no Estado do Pará e de negação de um currículo que, sob o argumento da unificação democrática, impõe aos povos do campo o silêncio sobre suas lutas, suas conquistas, suas dores e suas alegrias e, no lugar desse colorido, infunde uma visão autoritária de cultura e de história. A insatisfação com dada linearidade das ações pedagógicas, circunstanciadas pelas exigências estatísticas, é também causa dessa proposta que procura prevenir, pela produção de saberes sobre o trabalho escravo, circunstâncias que possam enredar os alunos nessa trama.

\section{CONSIDERAÇÕES FINAIS: DA EDUCAÇÃO INGÊNUA À FORMA- ÇÃO CRÍTICA}

Enquanto a educação pública no Estado do Pará, e no Brasil de um modo geral, oscilar entre o esforço de homogeneização, para atender as demandas do ENEM, e a incompetência administrativa que torna vãs as políticas educacionais, o sistema de ensino não poderá garantir dignidade aos educandos, tão pouco se resolverão problemas pontuais, como a evasão escolar. Uma escola que se justifique precisa se justificar para os alunos, que são os sujeitos do processo educativo. E uma escola que justifica sua existência é o lugar da ação pedagógica em que o mundo da teoria se conecta ao universo das vidas daqueles que estão envolvidos nessa ação pedagógica. 
Ainda é preciso dizer que no conjunto dos descompassos entre o ideal e o real é dramático que se tenha normalizado o funcionamento do sistema modular, algo que ainda no final do século XX apresentava-se como uma curva do real. Ainda mais dramáticas são as alternativas que têm sido propostas em substituição ao Sistema Modular, alternativas ancoradas apenas no pragmatismo econômico, de minimização do papel do Estado aprofundando a dramaticidade revestida de novidade tecnológica e de progresso.

A educação básica oferecida pelo sistema público paraense, de modo geral, funciona muito precariamente. E esse fato está muito além do Sistema Modular. Essa precariedade se manifesta desde os aspectos estruturais ao próprio sentido do ensino e da aprendizagem. Ao mesmo tempo em que professores e alunos precisam frequentar espaços insalubres, que são destinados pelo Estado como lugar de aula, as políticas educacionais desenvolvidas no Pará não demonstram sequer a capacidade de articulação com o modelo educativo daquilo que se convencionou chamar de tecnicismo, onde o aluno aprende a ler um manual e apertar um parafuso, mas não sabe pensar sobre suas condições de trabalho. Isso implica dizer que o estado tem falhado até em domesticar. E essa educação que não ensina termina por afastar o aluno, que não aprende. Em muitos lugares, a escola além de desprazerosa, é escura, feia, mefítica e põe a integridade de alunos e professores em risco.

A experiência docente no Modular, ao mesmo tempo em que demonstrou a distância entre os pressupostos de uma educação que liberta porque implica em consciência de si e do mundo, também falha em relação aos pressupostos teóricos da educação do campo. Explícito está também a distância entre os discursos oficiais sobre a educação e a educação como de fato se dá no campo. Essa consciência foi fundamental para uma tomada de posição teórico-política que resultou nesse projeto de trabalho pedagógico que, partindo da realidade da comunidade escolar, procurou historicizar seus problemas e, no caso do trabalho escravo, propor ações preventivas. É nesse quadro de desesperança que a proposta de formação, teoricamente fundada em Paulo Freire e Rüsen, tendo os problemas da comunidade escolar como ponto de partida, apresenta-se como a alternativa ao caos.

\section{REFERÊNCIAS}

ALVES, Rubem. O velho que acordou menino. São Paulo: Planeta, 2005.

BARRETO, Maria Lecticia Fonceca. Admirável mundo velho: velhice, fantasia e realidade social. São Paulo: Ática, 1992.

BEAUVOIR, Simone. A Velhice. Rio de Janeiro: Nova Fronteira, 1970.

BOSI, Ecléa. Memória e Sociedade: lembrança de velhos. 2. ed., São Paulo: Martins Fontes, 1994. 
BRAYNER, Conceição de Nazaré de Morais. Um estudo avaliativo do Ensino Médio modular a partir das Diretrizes Operacionais da Educação Básica nas Escolas do Campo no Pará. Belém: UEPA, 2013. Dissertação de mestrado.

CALDART, Roseli Salete. Por uma educação do campo: traços de uma identidade em construção. In: KOLLING, Edgar Jorge; CERIOLI, Paulo Ricardo; CALDART, Roseli Salete (Orgs.). Educação do campo: identidade e políticas públicas. São Paulo: Por uma educação do Campo, 2002.

CARRAHER, Teresinha Nunes; et. al. Na vida dez, na escola zero. São Paulo: Cortez, 1989.

CASALDÁLIGA, Pedro. Uma Igreja da Amazônia em Conflito com o Latifúndio e a Marginalização Social. São Feliz do Araguaia: Prelazia de São Felix, 1971.

CERRI, Luiz Fernando. Os conceitos de consciência história e os desafios da didática da história. Revista de História Regional 6(2), pp. 93-112, 2001.

COMISSÃO PASTORAL DA TERRA. Trabalho Escravo Contemporâneo: Educar, para não escravizar. Rio Maria: CPT, 2013.

FREIRE, Paulo. Educação como prática da liberdade. $24^{a}$ ed. São Paulo: Paz e Terra, 2000.

. Pedagogia da autonomia: saberes necessários à prática Educativa. $25^{a}$ ed. São Paulo: Paz e Terra, 1996.

. A importância do ato de ler: em três artigos que se completam. $23^{a}$ ed. São Paulo: Autores Associados: Cortez, 1989. Col. polêmicas do nosso tempo, 4.

. Pedagogia do oprimido. $17^{\text {a }}$ ed. Rio de Janeiro: Paz e Terra, 1987.

Olho D'agua, 1997.

Professora sim, tia não: cartas a quem ousa ensinar. São Paulo:

FIGUEIRA, Ricardo Rezende. Pisando fora da própria sombra: a escravidão por dívida no Brasil contemporâneo. Rio de Janeiro: Civilização Brasileira, 2004.

GRAMSCI, Antônio. Cadernos do Cárcere. COUTINHO, Carlos Nelson. (Trad.). 2. ed. Rio de Janeiro: Civilização Brasileira, 2001. (v. 2: Os intelectuais. O princípio educativo. Jornalismo).

MARCHESI, Álvaro. O que será de nós, os maus alunos? Porto Alegre: Artmed, 2005.

NERI, Marcelo Côrtes (Coord.). O Tempo de Permanência na Escola e as Motivações dos Sem-Escola. Rio de Janeiro: FGV/IBRE, CPS, 2009. 
PEREIRA, Rosenildo da Costa. Sistema de Organização Modular de Ensino (SOME) e a inclusão social dos jovens e adultos do campo. MARGENS - Revista Interdisciplinar. V. 10. N. 14. Jun 2016. (p. 187-198).

QUEIROZ, Adeíse Gomes. O Sistema Modular de Ensino no Estado do Pará: contribuições para o desenvolvimento educacional no município de Abaetetuba. Taubaté: Universidade de Taubaté, 2010. Dissertação de mestrado.

REPÓRTER BRASIL. Escravo, nem pensar! uma abordagem sobre trabalho escravo contemporâneo na sala de aula e na comunidade. $2^{a}$ Ed. São Paulo, Repórter Brasil, 2012.

RÜSEN, Jörn. Didática da História: passado, presente e perspectivas a partir do caso alemão. In: Práxis Educativa. Ponta Grossa, PR. V.1, n.2, p.7-16, jul/dez. 2006.

RÜSEN, Jörn. Razão Histórica: Teoria da História - os fundamentos da ciência histórica. Brasília: Ed. UnB, 2001.

SARTRE, Jean Paul. O que é literatura? São Paulo: Ática, 1989.

. O existencialismo é um humanismo. GUEDES, Rita Correia (trad.). Paris: Les Éditions Nagel, 1970.

SCHMIDT, Maria Auxiliadora; MARTINS, Estevão de Rezende (Orgs.). Jörn Rüsen e o ensino de história. Curitiba: Ed. UFPR, 2011.

SCHMIDT, Maria Auxiliadora e URBAN, Ana Claudia. Aprendizagem e formação da consciência histórica: possibilidades de pesquisa em Educação Histórica. Educar em Revista, Curitiba, Brasil, n. 60, p. 17-42, abr./jun. 2016.

SILVA, Moisés Pereira. O trabalho escravo contemporâneo e a atuação da CPT no campo (1970-1995). São Paulo: PUC-SP, 2016. Tese.

. Questão agrária e trabalho escravo: educar para a liberdade. Marabá, 2016. Manuscrito.

. O trabalho escravo contemporâneo: conceito e enfrentamento à luz do trabalho jurídico e pastoral do frei Henri Burin des Roziers. Estudos Históricos. Rio de Janeiro, vol 32, n 66, p. 329-346, janeiro-abril 2019.

VÁZQUEZ, A. Sánchez. Filosofia da práxis. Rio de Janeiro: Paz e Terra, 1977.

WILLINGHAM, Daniel T. Por que os alunos não gostam da escola? Respostas da ciência cognitiva para tornar a sala de aula mais atrativa e efetiva. Porto Alegre: Artmed, 2011. 


\section{Periódico}

LIMA, Kelly e MAGNO, Cintia. Educação do Pará é a pior do Brasil. Diário do Pará, 22/06/2017. In: http://www.diarioonline.com.br/noticias/para/noticia426229-educacao-do-para-e-a-pior-do-brasil.html. Acessado em 20/08/2018.

RAMPAZZO, Alexandre. Nas terras do bem virá. Direção: Alexandre Rampazzo. Produção: Eclipse Produções/ Varal Filmes. País: Brasil. Duração: 110min. Ano: 2007.

\section{Manuscritos de alunos}

DISCENTE A. Como tudo começou. Vila Primeiro de Março: Manuscrito, 2018.

DISCENTE B. A história da Vila Oziel. Vila Oziel Pereira: Manuscrito, 2018.

DISCENTE C. A luta do povo. Vila Primeiro de Março: Manuscrito, 2018.

DISCENTE E, A história da $1^{\circ}$ Primeiro de Março. Vila Primeiro de Março: Manuscrito, 2018. 
